\title{
Curativo do paciente queimado: uma revisão de literatura
}

\author{
DRESSING OF BURNED PATIENTS' WOUNDS: A LITERATURE REVIEW
}

CURACIONES DEL PACIENTE COM QUEMADURAS: UNAREVISIÓN DE LA LITERATURA

\author{
Enéas Ferreira', Rosemeire Lucas ${ }^{2}$, Lídia Aparecida Rossi ${ }^{3}$, Denise Andrade ${ }^{4}$
}

1 Enfermeiro Chefe da Unidade de Queimados do Hospital das Clínicas da Faculdade de Medicina de Ribeirão Preto, USP.

2 Aluna do Curso de Graduação em Enfermagem pela Escola de Enfermagem de Ribeirão Preto. EERP-USP

3 Professora Associada junto ao Departamento de Enfermagem Geral e Especializada da EERP-USP. rizzardo@eerp.usp.br 4 Professora Doutora junto ao Departamento de Enfermagem Geral e Especializada da EERP-USP.

\author{
RESUMO \\ O objetivo deste estudo foi \\ descrever, mediante revisão \\ de literatura, os agentes \\ tópicos e tipos de cobertura \\ que têm sido recomendados \\ no tratamento de \\ queimaduras e discutir as \\ implicações do uso desses \\ produtos. $O$ estudo foi \\ desenvolvido mediante \\ levantamento bibliográfico \\ dos últimos 12 anos, nas \\ bases de dados Lilacs, \\ Medline e Dedalus. As \\ publicações encontradas \\ foram organizadas como de \\ pesquisa e de revisão e, \\ posteriormente, categorizadas \\ de acordo com a temática: \\ agentes tópicos e substitutos \\ temporários de pele. Foram \\ discutidos os possiveis efeitos \\ colaterais, indicações e \\ recomendações quanto à \\ manipulação.
}

\section{PALAVRAS-CHAVE}

Queimaduras.Curativos. Ferimentos e lesões.

Cicatrização de feridas.

\author{
SUMMARY \\ This study aimed at \\ describing, by means of a \\ literature review, the topical \\ agents and bandage types \\ which have been \\ recommended in the treatment \\ of burns and their implications \\ in nursing care. This study \\ was conducted by collected \\ bibliographic data concerning \\ the last 12 years from Lilacs, \\ Medline and Dedalus \\ databases. The articles found \\ were organized as research \\ and review articles and later \\ categorized according to the \\ theme: topical agents and \\ temporarily skin dressing. We \\ discussed the possible effects \\ as well as the indications and \\ recommendations as to the \\ manipulation of the agents and \\ bandage types which have \\ been recommended in the \\ treatment of burns.
}

\section{KEYWORDS}

Burns. Bandages.

Wounds and injuries.

Wound nealing.

\begin{abstract}
RESUMEN
Los objetivos de este trabajo fueron: describir, mediante revisión de la literatura, los agentes topicos y tipos de cobertura recomendados para el tratamiento de las quemaduras y sus implicancias en la asistencia de enfermeria. El estudio se desarrolló mediante búsqueda bibliografica de los últimos 12 años, en los bancos de datos Lilacs, Medline y Dedalus. Los artícluos encontrados fueron organizados como artículos de investigación y de revisión. Posteriomente fueron clasificados por su temática: agentes topicos y sustitutos temporales de piel. En el analisis de las informaciones incluidas en la literatura fueron considerados los posibles efectos colaterales, indicaciones $y$ recomendaciones sobre la manipulación de eses productos.
\end{abstract}

\section{PALABRAS-CLAVE}

Quemadura. Vendajes. Heridas e traumatismos. Cicatrizacion de heridas

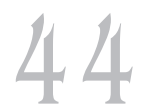

Rev Esc Enferm USP 2003; 37(1): 44-51 


\section{INTRODUÇÃO}

Os protocolos para tratamento de feridas provocadas por queimaduras podem variar de um hospital para outro. Aspectos que indicam a gravidade da ferida como, por exemplo, a localização, profundidade, extensão, presença ou não de infecção, agente causador do trauma, estado nutricional dos pacientes, presença de doenças crônicas degenerativas e faixa etária, afetarão o processo de cicatrização e influenciarão na escolha do tratamento da ferida.

A lesão provocada pela queimadura pode ser descrita com base na sua profundidade, sendo classificada como de primeiro grau, quando é comprometida apenas a epiderme, apresentando eritema e dor; de segundo grau, quando atinge a epiderme e parte da derme, provocando a formação de flictenas; e de terceiro grau, quando envolve todas as estruturas da pele, apresentando-se esbranquiçada ou negra, pouco dolorosa e seca. Na escolha do tratamento, deve-se considerar não só a profundidade da lesão, mas também a sua fase evolutiva. As queimaduras de primeiro grau, dependendo da extensão, geralmente evoluem rapidamente, regenerando-se em até cinco dias, sendo indicado uso de creme hidratante local.

A queimadura de segundo grau tem sido classificada como superficial e profunda, e a sua evolução dependerá desta graduação de profundidade e da ocorrência ou não de complicações, sendo as infecções uma das causas mais freqüentes de piora tanto no âmbito tópico quanto no sistêmico. As queimaduras de segundo e terceiro graus terão que passar por um processo de desbridamento que consiste na retirada de tecidos desvitalizados. Esse processo poderá ser mais demorado e necessitar de maior intervenção dependendo da profundidade e extensão da queimadura. Queimaduras classificadas inicialmente como segundo grau, podem aprofundar-se na coexistência de infecção local.

As lesões resultantes das queimaduras são isquêmicas como conseqüência da trombose causada pelo trauma. As queimaduras profundas apresentam trombose em todas as camadas da pele atingidas e a diminuição da oxigenação nesses tecidos dificulta o crescimento dos capilares e a cicatrização da feri- da, pois todos os tecidos humanos requerem oxigênio para que se mantenham viáveis. Nas queimaduras profundas há uma grande quantidade de tecidos necróticos, o que facilita o desenvolvimento de infecção, pois esses tecidos fornecem nutrientes para as bactérias que requerem pouco oxigênio para a sobrevivência, consumindo-o e diminuindo ainda mais a quantidade de oxigênio disponível para os tecidos ${ }^{(1)}$.

Os curativos de pacientes que sofreram lesões térmicas têm sido realizados, freqüentemente, por profissionais de enfermagem com base em uma rotina préestabelecida nos serviços especializados em queimaduras. Neste sentido, urge a necessidade de atualização desses profissionais para que possam atuar com eficiência e implementar ações fundamentadas em pesquisas.

O mercado oferece uma diversidade de produtos para tratamento de queimaduras que tem provocado insegurança nos profissionais da saúde sobre qual opção é a mais indicada. Vale considerar que a literatura apresenta alguns questionamentos sobre o tratamento das queimaduras ainda sem respostas e controvérsias que merecem ser esclarecidas. Em adição, alguns estudiosos mencionam a escassez de informações específicas acerca da indicação e efeitos adversos dos produtos convencionalmente utilizados em queimaduras, de maneira que seja possível relacionar estas informações com o tipo e a fase da queimadura ${ }^{(1)}$. Assim, se conclui que é preciso conhecer a eficiência de cada produto frente à diversidade de situações. Cabe destacar que o sucesso do tratamento depende, dentre outros fatores, da criteriosa escolha, bem como, da adequada utilização dos produtos selecionados.

Tem sido afirmado que "o cuidado com as feridas não pode ser um procedimento automático, mas um 'exercício científico', em que o enfermeiro deve atuar de forma consciente visando aplicar medidas que possam facilitar o processo de cicatrização"(2). Assim, o objetivo deste estudo foi descrever, mediante revisão de literatura, os agentes tópicos e tipos de cobertura que têm sido recomendados no tratamento de queimaduras e discutir as implicações do uso desses produtos no processo de cicatrização. 


\section{METODOLOGIA}

Foi realizado um levantamento bibliográfico dos últimos 12 anos, mediante pesquisa nos Bancos de Dados Lilacs; Mediline e Dedalus. Para tanto, foram utilizadas as seguintes palavras chaves: queimaduras, curativos e agentes tópicos (burns, dressing e topical agent). As publicações encontradas foram organizadas como de pesquisa e de revisão e, posteriormente, categorizadas de acordo com o tipo de agente tópico (soluções, cremes e produtos naturais) e substituto temporário de pele. Mediante a análise dessas publicações, foi possível contextualizar as implicações do uso de cada produto mencionado na literatura no processo de cicatrização.

\section{RESULTADOS E DISCUSSÃO}

Apresentamos a seguir os resultados obtidos na revisão de literatura considerando a categorização realizada: agentes tópicos (soluções, cremes e produtos naturais) e substituto temporário de pele, enfocando em cada tópico as vantagens e desvantagens do uso de cada produto.

\section{Agentes Tópicos}

O termo agente tópico representa uma substância utilizada na superfície da pele, podendo ter ação antimicrobiana ou não. Alguns agentes tópicos ajudam no desbridamento dos tecidos $^{(1)}$.

Dentre os diferentes tipos de agentes tópicos, existem os cremes que são constituídos por emulsões de água e óleo, em que a quantidade de água é superior ao óleo.

Há consenso na literatura quanto à utilização da Sulfadiazina de Prata 1\% para o tratamento de queimaduras, com a finalidade de desbridar tecidos necrosados e combater infecção local ${ }^{(1)}$. A Sulfadiazina de Prata 1\% é um composto de nitrato de prata e sulfadiazina de sódio, efetivo contra uma ampla microbiota de gram-negativas como Escherichia coli, Enterobacter, Klebsiella sp e Pseudomonas aeruginosa, além de incluir bactérias gram-positivas como Staphylococus aureus e também Candida albicans ${ }^{(1)}$.

Na revisão de literatura, encontramos alguns estudos que compararam a utilização da Sulfadiazina de Prata $1 \%$ com outras substâncias como o mel ${ }^{(3)}$, o curativo colóide ${ }^{(4)}, \mathrm{e}$ incorporada a outros produtos como a membrana amniótica ${ }^{(5)}$ e com um substituto temporário de pele composto de polietileno glicol, hidróxi de metacrilato e sufóxido de dimetil adicionado a Sulfadiazina de $\operatorname{Prata}^{(6)}$. Esses ingredientes foram incorporados a uma base de nylon e lycra que resultou na formação de uma lâmina elástica e flexível que permite o contorno do corpo. Durante a utilização desse produto observou-se redução do índice de infecção ${ }^{(6)}$.

Por volta de 1976, estudiosos sobre o tratamento de queimaduras preparam um composto de Nitrato de Cério e Sulfadiazina de Prata, com o objetivo de reduzir a infecção de feridas ${ }^{(7)}$. A combinação dessas duas substâncias leva à deposição de uma fina camada de sais de cálcio sobre a lesão, formando uma barreira contra bactérias ${ }^{(8)}$.

A Sulfadiazina de Prata 1\% é um dos agentes tópicos mais utilizados no tratamento de queimaduras, sendo recomendada em queimaduras de segundo e terceiro graus. É facilmente aplicada e removida, não provoca dor e apresenta poucos efeitos colaterais. Como um dos efeitos colaterais da Sulfadiazina de Prata 1\%, tem sido relatado episódios de discreta leucopenia depois de poucos dias de uso, e de alergias em menos de $5 \%$ dos pacientes sem necessidade de interrupção do uso ${ }^{(1)}$.

Na nossa prática clínica, em uma Unidade de Queimados, os pacientes têm relatado sensação de frescor após a aplicação desse creme. A aplicação de Sulfadiazina de Prata 1\%, segue a prescrição médica, que recomenda a sua utilização nos primeiros dias de tratamento da queimadura, enquanto há presença de tecido necrótico ou infecção. Esse agente tópico deve ser trocado duas vezes ao dia em razão da oxidação da prata. Entretanto, há dificuldades para atender a essa recomendação, quando a Sufadiazina de Prata 1\% é utilizada em curativos oclusivos, em função do trauma físico e emocional que cada curativo provoca ao paciente e do alto custo dos recursos utilizados.

Ainda, com relação à Sulfadiazina de Prata $1 \%$, há evidências na literatura de que ela é tóxica para o crescimento de queratinócitos e fibroblastos. Em um estudo realizado, em cultura de queratinócitos in vitro, para compa- 
rar a toxidade de agentes antimicrobianos para as células epiteliais, observou-se a seguinte ordem crescente de toxidade: pomadas com três tipos de antibióticos (sulfametoxazol trimetoprima 50.000 U, Polimixina B 200,000 U e Neomicina $40 \mathrm{mg}$ ), solução salina normal, petrolato, acetato de mafenide, solução de PVP-I, sulfadiazina de prata $1 \%$, nitrato de prata, nitrofurazona e líquido Dakin $(0,5 \%)$. A Sulfadiazina de Prata foi testada em uma concentração de $0,03 \%$ que é somente um terço da concentração utilizada (1\%). Com base nesses resultados, recomenda-se que na escolha do agente tópico, sejam considerados os benefícios dos antibióticos contra os efeitos tóxicos na migração epitelial. Desta forma, entendemos que a utilização de agentes com maior toxidade não está indicada em áreas que apresentem sinais de epitelização e não apresentem sinais de infecção ${ }^{(9)}$.

Outros cremes também utilizados são o Acetato de Sulfanamida $10 \%$, a Nitrofurazona $0,2 \%$ e o Creme de Gentamicina $0,1 \%{ }^{(1)}$. O creme de Nitrofurazona $0,2 \%$ não tem sido utilizado nos Estados Unidos da América, entretanto, ainda é utilizado em nosso Serviço de Queimados. Apresenta ampla ação bacteriostática, embora menor que a da Sulfadiazina de Prata 1\%. Em nosso serviço, quando as lesões apresentam-se limpas com formação de tecido de granulação, tem sido utilizado o creme de Nitrofurazona $0,2 \%$, sendo que os pacientes relatam dor e sensação de queimação após a aplicação. Há relatos na literatura de que esse creme é realmente bastante doloroso à aplicação ${ }^{(1)}$ e que também apresenta toxidade ao crescimento de queratinócitos em cultura ${ }^{(9)}$. Assim, a sua utilização em feridas limpas com presença de tecido de granulação pode ser contraindicada em razão da dor provocada após a aplicação. Esse creme pode causar dermatite de contato (prurido e edema) ${ }^{(1)}$, fato esse também observado em nosso serviço. Com base nas recomendações desses autores e considerando os efeitos desse produto, entendemos que sua utilização em feridas limpas ou quando apresentarem crescimento de tecido de granulação não seria uma escolha adequada.

Na literatura, também está documentado o uso de Acetato de Sulfanamida $10 \%$ e Creme de Gentamicina $0,1 \%$. O Acetato de Sulfanamida $10 \%$ foi amplamente utilizado em tratamento de queimaduras antes do adven- to da Sulfadiazina de Prata $1 \%$. Esse creme é ainda considerado como uma alternativa importante no combate à infecção, entretanto, pode causar acidose metabólica, pela inibição da anidrase carbônica e é doloroso à aplicação ${ }^{(1)}$.

Dentre as diversas opções para tratamento de queimaduras observa-se a recomendação da utilização das pomadas enzimáticas e dos Ácidos Graxos Essenciais (AGE), que são compostos por ácido linoleico, ácido caprílico, vitamina A, E e lecitina de soja. Os AGE são precursores de substâncias farmacologicamente ativas envolvidas no processo de divisão celular e diferenciação epidérmica. Possuem a capacidade de modificar reações inflamatórias e imunológicas, alterando funções leucocitárias e acelerando o processo de granulação tecidual. Os AGE podem ser utilizados diretamente sobre o leito da ferida ou embebidos em gases estéreis, devendo ser trocados no máximo a cada 24 horas. Já as pomadas enzimáticas como a colagenase, apresentam caráter enzimático e debridante, estimulando, indiretamente, a formação do tecido de granulação e, posteriormente, a reepitelização ${ }^{(10)}$.

Paralelamente ao uso dos agentes tópicos deve-se instituir práticas que devem incluir a avaliação precisa das lesões não só no que se refere à descrição das suas características e da evolução diária, mas também à descrição das reações e dos efeitos colaterais que esses agentes podem provocar.

\section{Produtos Naturais}

No tratamento de queimaduras, encontramos várias referências na literatura, no período estudado, sobre a utilização do mel e da papaína $^{(3,11-13)}$. O mel mostrou-se mais eficaz no tratamento das queimaduras, promovendo a cicatrização em tempo menor que a sulfadiazina de prata $1 \%{ }^{(3)}$. "As substâncias contendo açúcar, como mel e derivados da cana-de-açúcar, vêm sendo usadas há vários anos no tratamento de lesões de pele com excelentes resultados clínicos. Considera-se que propicia os seguintes efeitos: rápida diminuição da congestão passiva e do edema locais, estímulo da epitelização e granulação tissular e ação antibacteriana"(3).

Sabe-se que o mel é composto por vitaminas, concentrações de ácido fórmico, enxofre, cloro e outros elementos químicos, mas o 
Enéas Ferreira

Rosemeire Lucas

Lídia Aparecida Rossi

Denise Andrade

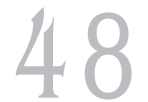

Rev Esc Enferm USP 2003; 37(1): 44-51. seu principal efeito é desconhecido. O mel inibe o crescimento de cepas gram-negativas e gram-positivas, devido ao baixo $\mathrm{pH}$, e promove uma barreira viscosa que impede a invasão de microorganismos, bem como a perda de fluidos das lesões. Também, contém enzimas como a catalase, que auxilia no processo de cicatrização ${ }^{(12)}$. Promove efeito osmótico suficiente para inibir o crescimento microbiano e, quando diluído, produz peróxido de hidrogênio, que é um agente antimicrobiano $^{(11)}$.

Outro agente tópico utilizado é a papaína, que é um complexo de enzimas proteolíticas, retirado do látex do mamão papaia (Carica papaya), cujo sítio ativo é portador de um radical sulfidrila $(\mathrm{SH})$, tornando-se difícil sua associação com outro recurso terapêutico, visto que ela sofre oxidação pela substituição do enxofre, por derivados de ferro, oxigênio e iodo. Seu mecanismo de ação ocorre através da dissociação das moléculas de proteína, resultando em desbridamento químico, por ser uma enzima de fácil deterioração, deve ser sempre mantida em lugar fresco, seco, ventilado e protegido da luz ${ }^{(13)}$.

O carvão ativado, outro agente muito utilizado em feridas infectadas, tem a ação de absorver o exsudato da lesão e diminuir seu odor fétido.

\section{Soluções}

As soluções são utilizadas para a realização de anti-sepsia de pele e mucosas com a finalidade de prevenir a colonização, porém, algumas vezes, também são utilizadas em curativos úmidos ${ }^{(1)}$. Entre as soluções citadas na literatura encontramos o ácido acético, a solução de Dakin, o nitrato de prata, a tripla solução de antibiótico (sulfametoxazol trimetoprima 50.000 U, Polimixina B 200,000 U e Neomicina $40 \mathrm{mg}$ ), o Gluconato de Clorexidina e a solução de PVP-I (Polivinil Pirrolidona Iodada $)^{(14-15)}$. O ácido acético 0.5\% possui ação bactericida para micro-organismos gram-negativos e gram-positivos em especial para $P$. aeruginosa.

Em um estudo, no qual foi avaliada a toxidade de quatro agentes tópicos antimicrobianos in vitro, solução de PVP-I a $1 \%$, solução de hipoclorito de sódio $0,5 \%$ (líquido de Dakin), ácido acético 0, 25\% e peróxido de hidrogênio a 3\%, em culturas de fibroblastos humanos e em culturas de $S$. aureus, constatou-se que as soluções de ácido acético e peróxido de hidrogênio apresentaram mais toxicidade para os fibroblastos que para a bactéria e que as diluições de PVP-I (1: 1000) e hipoclorito de sódio (1:1000) não apresentaram nenhuma toxidade para o fibroblasto, mas sim atividade bactericida ${ }^{(16)}$. Entretanto, é importante destacar que a utilização PVP-I deve ser cuidadosa com atenção especial à possibilidade de desenvolvimento de reações alérgicas e ao fato de que seu uso pode ser limitado pela absorção sistêmica acarretando problemas renais e de tiróide. A solução de clorexidina é outro agente tópico que age em bactérias Gram-positivas e Gram-negativas, sendo contra-indicado para o tratamento de feridas abertas, devendo ser utilizado na prevenção da colonização dos locais de inserção de catéteres vasculares e fixadores externos.

As soluções de acido acético a $0.25 \%$ também foram citadas como eficazes na redução de microorganismos das feridas ${ }^{(16)}$. Em um estudo realizado, o ácido acético $0.5 \%$ demonstrou ser tóxico para os fibroblastos em cultura, reduziu a proliferação de células epiteliais e retardou a cura dos tecidos para enxertos. Assim, as concentrações a $0.5 \%$ são tóxicas para regeneração do epitélio. Sugerese que a solução de ácido acético é adequada para pequenas feridas infectadas ${ }^{(16)}$.

A solução de Dakin (hipoclorito de sódio a $0,5 \%$ ) é considerada bactericida para Stafilococcus sp e Streptococcus sp, fungos e alguns agentes virais. As soluções com concentração $0.5 \%$ têm ação bactericida eficaz, mas possuem toxicidade para os fibroblastos e queratinócitos em cultura. Já a solução de Dakin $0.25 \%$ tem apresentado toxicidade mais leve, mas provoca dor. A prolongada utilização deste produto pode levar à irritação da pele. Em menor concentração, essa solução é considerada como alternativa para o tratamento de pequenas feridas infectadas por causa de sua leve toxidade para os tecidos ${ }^{(17-18)}$.

Uma outra solução é a de nitrato de prata a $0.5 \%$ que possui ação bactericida eficaz para gram-positivas (S. aureus). A infecção local pode ser controlada com esta solução, que é extremamente hipotônica e eletrolítica (sódio e potássio). Entretanto, com o seu uso podem ocorrer reações de hipersensibilidade por causa de seu potencial tóxico ${ }^{(1)}$.

A tripla solução de antibiótico (sulfametoxazol trimetoprima $50.000 \mathrm{U}$, 
Polimixina B200,000 Ue Neomicina 40 mg) pode ser utilizada nos curativos de feridas infectadas graves. Possui ação bactericida moderada para gram-negativas e gram-positivas e é indicada por provocar sensação de frescor ${ }^{(1)}$. A solução de Gluconato de clorexidina possui ação bactericida para diferentes tipos de cepas positivas e negativas ${ }^{(19)}$, no entanto seu uso pode causar dermatite de contato ${ }^{(20)}$.

\section{Substitutos temporários de pele}

Os substitutos temporários de pele são materiais eficazes no tratamento de queimaduras superficiais recentes e também na cobertura da pele enquanto aguarda-se o enxerto definitivo. Podem ser trocados a intervalos regulares ou mantidos até a cicatrização ou enxerto, caso a aderência seja boa ou não haja infecção ${ }^{(21)}$. Considera-se que há três linhas de substitutos temporários de pele ${ }^{(22)}$ :

- substitutos de origem animal, como enxerto homólogo, membrana amniótica, pele de porco, pele de embrião bovino e colágeno;

- substitutos elaborados à base de substâncias sintéticas, tais como silicone, poliuretano e hydrom;

- substitutos associados à matéria orgânica e uma película sintética, tal como colágeno e silicone.

As propriedades dos substitutos de pele devem ser: aderência, transporte do vapor de água, elasticidade, durabilidade, baixa antigenicidade e toxicidade, capacidade hemostática e ação antibacteriana. Podem ainda ser classificados em substitutos biológicos que constituem os aloenxertos (homoenxertos), xenoenxertos (heteroenxertos) e membrana amniótica; substitutos sintéticos que são constituídos por membranas de polímero de silicone, membranas de cloreto de polivinil, metilmetacrilato, membrana de polipropileno com poliuretano, membrana de silicone com nylon ligado a peptídios de colágeno dérmico, e membrana impermeável com camada profunda de partículas de hidroativos agregados em polímero inerte; substitutos biossintéticos que incluem a película microfibrilar de celulose pura e a membrana de silicone com matriz dérmica de colágeno e glicosaminaglicanos ${ }^{(21)}$.

Alguns substitutos temporários de pele disponíveis, como por exemplo, Opsite ${ }^{\circledR *}$ e Tegaderm $^{\mathbb{\circledR}^{*}}$, são constituídos por filmes de poliuretano, por membrana de cloreto de polivinil, pelos filmes de cloreto de polivinil que conferem ao material maior elasticidade $\mathrm{e}$ permeabilidade ao vapor de água, sendo que estes filmes aderem à pele e não a ferida.

Há ainda outros produtos, como por

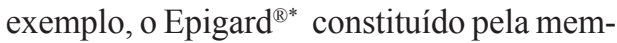
brana de polipropileno com poliuretano, um material de dupla constituição que contém um filme de polipropileno microporoso, na superfície, laminado a uma camada profunda de espuma de poliuretano, o Biobrane ${ }^{\circledR *}$ constituído pela membrana de silicone com nylon ligado a peptídeo do colágeno dérmico, material semipermeável, tem boa aderência e flexibilidade e alivia a dor em $90 \%$ dos pacientes, o Duoderm ${ }^{\circledR *}$ constituído por partículas hidroativas agregadas em polímero inerte e funciona como um curativo hidroativo, constituído por duas camadas, uma externa impermeável à água e uma interna formada por partículas hidroativas agregadas a um polímero inerte. Esse tipo de cobertura adere à pele normal e as partículas protegem o leito cruento. $\mathrm{O}$ exsudato liberado pelo ferimento interage com as partículas hidroativas, formando um gel úmido que facilita a migração de células epiteliais, estimulando a cicatrização ${ }^{(21)}$.

Os substitutos de pele têm sido considerados úteis no tratamento de queimaduras superficiais, pois reduzem a freqüência de troca do curativo ${ }^{(17)}$. Entretanto, esses materiais têm alto custo e não são eficazes para tratamento de queimaduras profundas.

Em um estudo realizado com pacientes ambulatoriais, com queimaduras de segundo grau, constatou-se que o Duoderm ${ }^{\circledR}$ apresentou melhores resultados que a Sulfadiazina de Prata $1 \%$, pois os pacientes apresentaram menor limitação de atividade, repigmentação mais rápida; referiram melhora da dor, melhor cicatrização da ferida e menor necessidade de troca de curativo, com menor custo ${ }^{(4)}$.

\section{CONCLUSÕES}

A partir da revisão da literatura, observase que há um consenso quanto ao uso da Sulfadiazina de Prata $1 \%$ no tratamento de queimaduras com a finalidade de desbridar tecidos necrosados e combater a infecção local. Outros agentes tópicos recomendados são o Acetato de Sulfanamida 10\%, a Nitrofu-
Curativo do paciente queimado: uma revisão de literatura
Opsite®-Smith \& Nephew Tegaderm/Tegasorb ${ }^{\circledR}-3 \mathrm{M}$ Epigarg $^{\circledR}$ - Orthomed Medizintechnik GmbH Duoderm ${ }^{\circledR}$ - Covatec Biobrane $^{\circledR}$ - Woodroof Laboratories Inc. Sterling Drug 
razona $0,2 \%$ e o Creme de Gentamicina $0,1 \%{ }^{(1)}$. Tem sido também utilizada a combinação de Sulfadiaziana de Prata 1\% com o mel. Há relatos de que essa combinação resultou em uma redução do tempo de cicatrização ${ }^{(3)}$. Cada um desses agentes apresenta um certo grau de toxidade para o crescimento de queratinócitos e efeitos adversos, por essa razão, na escolha do agente, deve-se levar em conta as características da ferida.

Quanto aos produtos naturais que têm sido descritos na literatura, o mel e a papaína foram os mencionados com maior freqüência. Entretanto, o principal efeito do mel é desconhecido ${ }^{(11)}$.

As soluções citadas na literatura como indicadas para o tratamento de queimaduras foram ácido acético, a solução de Dakin, o nitrato de prata, a tripla solução de antibiótico, o Gluconato de Clorexidina e a solução de PVP-I (Polivinil Pirrolidona Iodada) ${ }^{(14-15)}$. É importante destacar que no emprego das soluções de PVP-I e nitrato de prata devem ser observados sinais de reações de hipersensibilidade ${ }^{(1)}$.

Os substitutos temporários de pele são materiais eficazes no tratamento de queimaduras superficiais recentes e também na cobertura da pele enquanto aguarda-se o enxer- to definitivo. Podem ser trocados a intervalos regulares ou mantidos até a cicatrização ou enxerto, caso a aderência seja boa ou não haja infecção ${ }^{(21)}$.

A seleção do agente tópico ou tipo de cobertura a ser utilizada no tratamento de queimaduras deve ser realizada com base na avaliação das características da ferida, em evidências apresentadas na literatura. A escolha dos agentes tópicos deve permitir a prevenção de infecção ou minimizar a proliferação de bactérias nas feridas. Aspectos relacionados com a toxicidade devem ser cuidadosamente avaliados, considerando-se a ação que cada produto pode ter no processo de epitelização $0^{(9)}$.

Deve-se ainda considerar a relação custo/ benefício como critério de escolha. Nesse sentido, a equipe de saúde que atua em Unidades de Queimados necessita manter-se atualizada, não se prendendo a tratamentos convencionais, sem fundamentação científica. Mister se faz usar o raciocínio crítico na tomada de decisão e na implementação de ações com vistas à efetividade do tratamento. Portanto, a indicação e a aplicação de produtos químicos em queimaduras deve ser realizada com base na avaliação criteriosa da ferida, das condições clínicas do cliente, bem como, na análise sistemática das evidências da literatura.

\section{REFERÊNCIAS}

(1) Ward RS, Saflle JR. Topical agents in burn and wound care. Phys Ther. 1995; 75(6):526-38.

(2) Monetta L. A importância da atuação científica do enfermeiro na execução dos curativos feitos com papaína. Rev Paul Enferm 1990; 9(3):83-7.

(3) Subrahmayam M. Honey dressing versus boiled potato peel in the treatment of burns: a prospective randomized study. Burns 1996;22(6):491-3.

(4) Wyatt D, McGowan DN. Comparison of hydrocolloid dressing and silver sulfadiazine cream in the outpatient management of seconddegree burns. J Trauma 1990;30(7):857-65.

(5) Haberal M, Oner Z, Bayraktar U, Bilgin N. The use of silver nitrate-incorporated amniotic membrane as a temporary dressing. Burns Incl Therm Inj 1987; 13(2):159-63.
(6) Deith EA. Results of a multicenter outpatient burn study on the safety and efficacy of DimacSSD, a new delivery system for silver sulfadiazine. J Trauma 1989; 29(4):430-47.

(7) Monafo WWW, Tandon SN, Ayyazian VH, Tuchschmidt J, SkinnerAM, Deitz,F Cerium nitrate: a new topical antiseptic for extensive burns. Surgery 1976; 80(4):465-73.

(8) Boecks W, Focquet M, Cornelissen M, Nuttin B. Related articles bacteriological effect of cerium-flamazine cream in major burns. Burns Incl Therm Inj 1985; 11(5):337-42.

(9) Smoot EC, Kucan JO, Roth A, Mody N, Debs N. In vitro toxicity testing for antibacterials against human keratinocytes. Plast Reconstr Surg 1991; 87(5):917-24.

(10) Marinho AM. Atenção nos cuidados de enfermagem das escaras quanto às associações terapêuticas. Rev Bras Enferm 1997; (50)2:257-74 
(11) Paim S P, Mafra Jr. CA, Tostes ROG. Uso tópico do açúcar em feridas. Rev Méd Minas Gerais 1991;(1)2:88-90.

(12) Subrahmanyam M. Typical application of honey in treatment of burns. Br J Surg 1991; 78(4):497-8.

(13) Monetta L. Uso de papaína nos curativos feitos pela enfermagem. Rev Bras Enferm 1987; (40)1: 66-3.

(14) Phillips I, Lobo AZ, Fernandes R, Gundara NS. Acetic acid in the treatment of superficial wounds infected by Pseudomonas aeruginosa. Lancet 1968 ;1(7532):11-4.

(15) Sloss JM, Cumberland N, Milner SM. Acetic acid used for the elimination of Pseudomonas aeruginosa from burn and soft tissue wounds. J R Army Med Corps. 1993;139(2):49-51.

(16)Lineaweaver W, Howard R, Soucy D, McMorris S, Freeman J, Crain C, Robertson J, Rumley T.Topical antimicrobial toxicity. Arch Surg 1985;120(3):267-70.
(17) Hansbrough JF, Zapata-Sirvent RL, Cooper ML. Effects of topical antimicrobial agents on the human neutrophil respiratory burst. Arch Surg 1991;126(5):603-8.

(18) Kozol RA, Gillies C, Elgebaly SA. Effects of sodium hypochlorite (Dakin's solution) on cells of the wound module. Arch Surg 1988; 123(4):420-3.

(19) Holder IA. Wet disc testing of mafenide hydrochloride, chlorhexidine gluconate, and triple antibiotic solution against bacteria isolated from burn wounds. J Burn Care Rehabil 1990;11(4):301-4.

(20) Lasthein Andersen B, Brandrup F. Contact dermatitis from chlorhexidine. Contact Dermatitis. 1985;13(5):307-9.

(21) Gomes RD, Serra MCVF, Pellon MA. Queimaduras. Rio de Janeiro: Revinter; 1995.

(22) Peixoto R, Santos DLN. Biofil. Uso e avaliação clínica de uma película celulósica em lesões cutâneas. Rev Bras Cir 1988; (78)2:141-5.
Curativo do paciente queimado: uma revisão de literatura 